\title{
LA ORNAMENTACIÓN EN LAS OBRAS DE CABANILLES II: TABLA DE ORNAMENTOS EMPLEADOS POR CABANILLES
}

\author{
Miguel BERnAL RIPOLL
}

\begin{abstract}
Appendix to the article "La ornamentación en las Obras de Cabanilles" appeared in Anuario Musical, 53 (1998), as an schedule of embellishments used in Cabanilles' works.
\end{abstract}

\section{Resumen}

Apéndice al artículo "La ornamentación en las obras de Cabanilles" publicado en Anuario Musical, 53 (1998), en forma de tabla de ornamentos empleados por Cabanilles.

En el número anterior del Anuario Musical tuvimos la ocasión de publicar un extenso estudio sobre la ornamentación en las obras de Cabanilles, a partir de los ornamentos escritos que aparecen en sus obras. Algunos colegas y amigos organistas nos han señalado la utilidad que tendría un breve resumen para el organista práctico $^{1}$, y recogiendo y agradeciendo esta sugerencia hemos elaborado la presente tabla de ornamentos, de manera similar a las tablas que los antiguos organistas hacían como guía para la interpretación de sus propias obras.

Dada su enorme variedad, es difícil sintetizar en una tabla breve los ornamentos existentes. No hemos renunciado a incluir esta diversidad en la tabla, la cual no es una simplificación o generalización de los ornamentos escritos por Cabanilles, sino que está elaborada con ornamentos copiados literalmente de sus obras ${ }^{2}$.

Siendo este estudio de carácter fundamentalmente descriptivo, no se profundiza en dos cuestiones que nos permitimos señalar como líneas futuras de investigación: En primer lugar, los problemas prácticos de realización (ejecución libre o literal, ligar o no la superior preparada, continuar o no los trinos con detención, dónde y en qué medida se pueden añadir ornamentos,

1. Agradecemos especialmente la crítica hecha en este sentido por Guy Bovet en La Tribune de l'Orgue.

2. Señalamos que algunos ornamentos están transportados por comodidad de escritura, para evitar en la tabla engorrosos cambios de armadura, líneas adicionales, etc. Pensamos que el transporte no afecta a la literalidad del ornamento, pues al fin y al cabo un mismo ornamento aparece frecuentemente transportado por diversos grados. Únicamente en el caso de los Grupos hemos optado por una esquematización. 
etc.). En segundo lugar, constatada la diferencia enorme entre la ornamentación de Cabanilles y otros organistas ibéricos, convendría realizar un trabajo de comparación con otros autores extranjeros (por ejemplo, Kerll, cuyos ornamentos presentan algunas similitudes con los de Cabanilles). Un estudio así podría arrojar datos interesantes de las fuentes donde bebió Cabanilles, así como demostrar nexos entre España y otros países.

\section{Trino largo}

Trino largo sencillo ininterrumpido

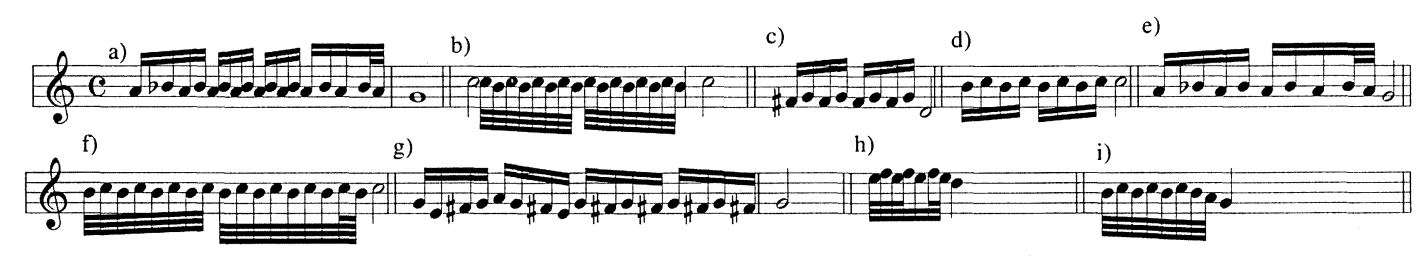

En valor de semibreve: a) normal lento, b) rápido, comienza por la superior preparada. En valor de Mínima: c) y d) no acaban por la nota principal (lo que contradice la descripción que Nassarre hace de este tipo de trino), e) normal lento, f) rápido, g) en cláusula comenzando por la superior (que estaba de algún modo preparada por la glosa). En Semínima: h) descendiendo segunda, i) descendiendo tercera (y rellenándola).

\section{Trino largo sencillo con detención}

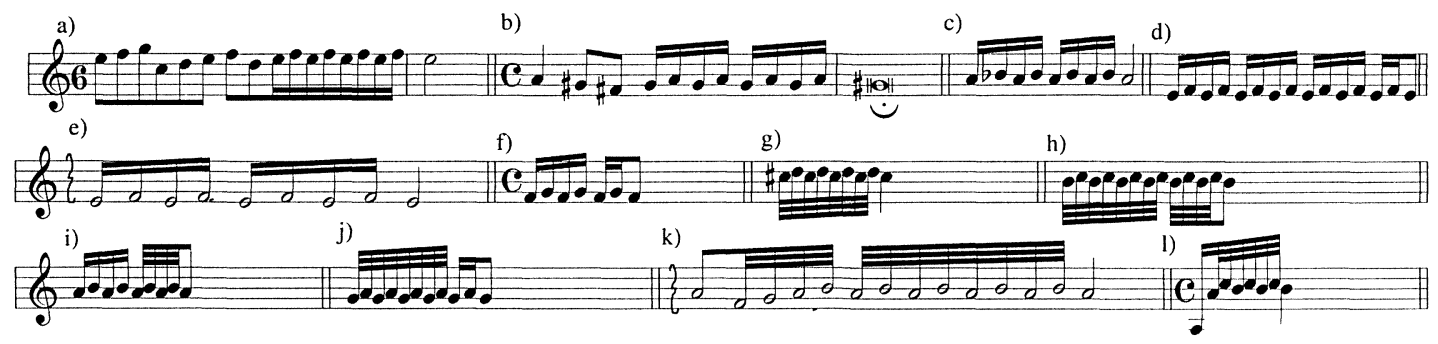

a), con gran grupo inicial, ocupando todo un compás de Sexquiáltera, b) en nota final, c) en Semibreve, d) lento, e) íd. ocupando más valor de la nota, e) en valor de Semibreve con puntillo (un compás) de Proporción Menor. En valor de Mínima: f) lento, g) rápido, h) rápido ocupando más parte de la nota, i) acelerado, j) retardado, k) ocupando dos partes de compás de Proporción, con grupo inicial. 1) en Semínima, todo el ornamento anticipado, y con comienzo tipo mordente oblicuo ("Anschlag"). 
Trino largo sencillo con detención y bordadura
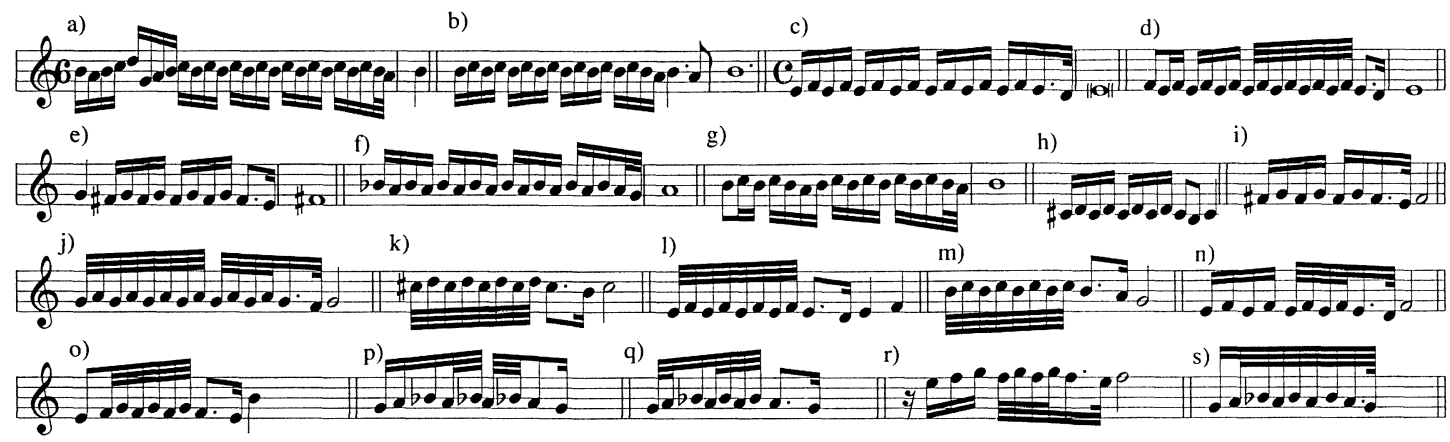

Con valor de más de Semibreve con puntillo (un compás) en Sexquiáltera: a) con grupo inicial, b) con dos bordaduras. En nota final (más de un compás) en Compasillo: c) normal, d) empezando por superior preparada, acelerado, e) empezando por superior preparada apoyada, $f$ ) empezando por superior, normal, g) empezando por la nota principal un poco apoyada. En valor de Semibreve: h) lento y con la bordadura lenta, i) lento y con bordadura rápida punteada, $\mathrm{j}$ ) rápido, k) rápido con bordadura punteada, 1) íd. dura sólo mínima con puntillo. En valor de mínima: m) con nota de paso para descender tercera, n) con escapatoria. En Semínima: o) todo el trino anticipado. En Corchea con puntillo, en diversas situaciones rítmicas: p), q), r) y s).

\section{Trino largo sencillo consecutivo}

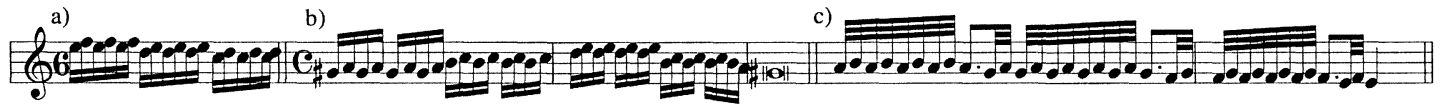

a) en Sexquiáltera, b) en notas de un acorde, c) con interrupciones y anticipando el inicio de cada trino

Trino largo con resolución ininterrumpido
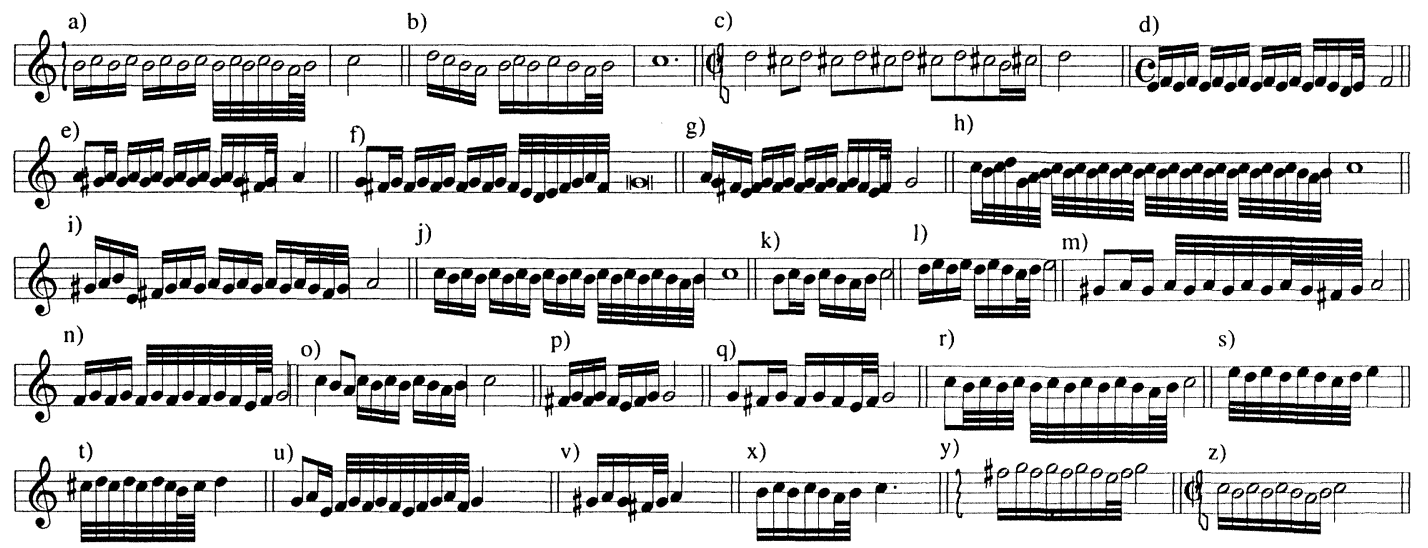

Anuario Musical, 54 (1999) 
a) con valor de Semibreve con puntillo (un compás) en Proporción Menor, formando grupo irregular (seis fusas en lugar de ocho), b) íd. con grupo inicial, también formando grupo irregular (seis semicorcheas en lugar de ocho), c) con valor de Breve en Proporción Mayor. Con valor de Semibreve (un compás) en Compasillo, diversas variedades: d) normal, e) empieza por superior (preparada), f) acelerado y con resolución compleja, g) con grupo inicial, h) con grupo inicial, rápido, i) con grupo inicial, final acelerado, j) acelerado. En valor de Mínima: k) apoyando la nota real, 1) normal, n) acelerado, o) comenzando por la superior directamente, si bien se ha oído antes, p) con final extraño, q) por la superior preparada y apoyada, r) íd. rápido, s) por la superior sin preparar, siempre en parte débil ( $2^{a}$ ó $4^{a}$ Semínima de Compasillo). Con valor de Semínima: t) normal, u) con resolución extraña, v) lento. x) con valor de Semínima con puntillo en Sexquiáltera a 12, y) con valor de Mínima en Proporción Menor, z) con valor de Semibreve en Proporción mayor, por la superior sin preparar (siempre en tercera parte de compás).

\section{Trino largo con resolución con detención}

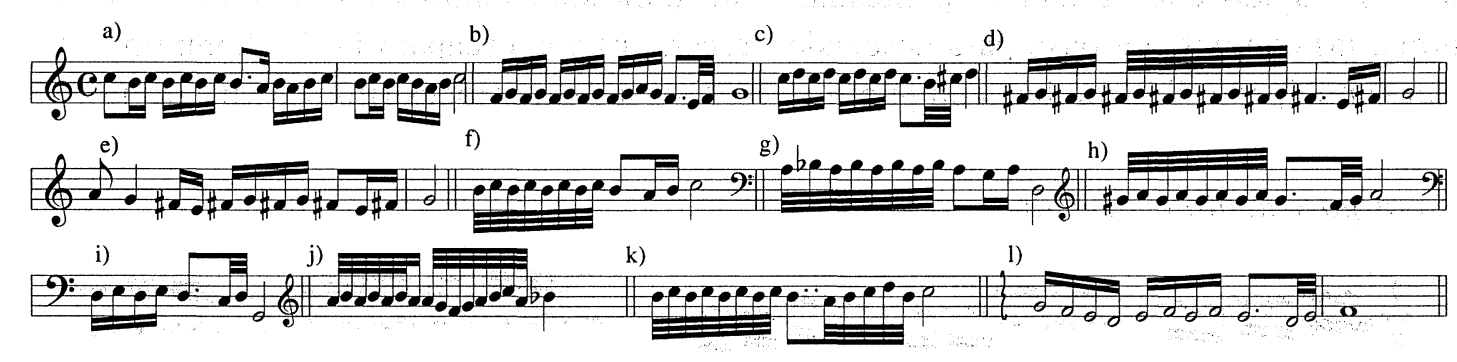

a) trino complejo con dos paradas, b) en valor de Semibreve, c) en Mínima con puntillo, d) en Semibreve, acelerado. En valor de mínima: e) normal un poco anticipado, f) rápido con resolución lenta, g) íd. para descender quinta, en el bajo h) rápido con resolución rápida, i) lento con resolución rápida (descenso de quinta, en bajo), j) y k) con resoluciones complejas, l) en Proporción Menor, con grupo inicial.

Trino largo con resolución con detención leve

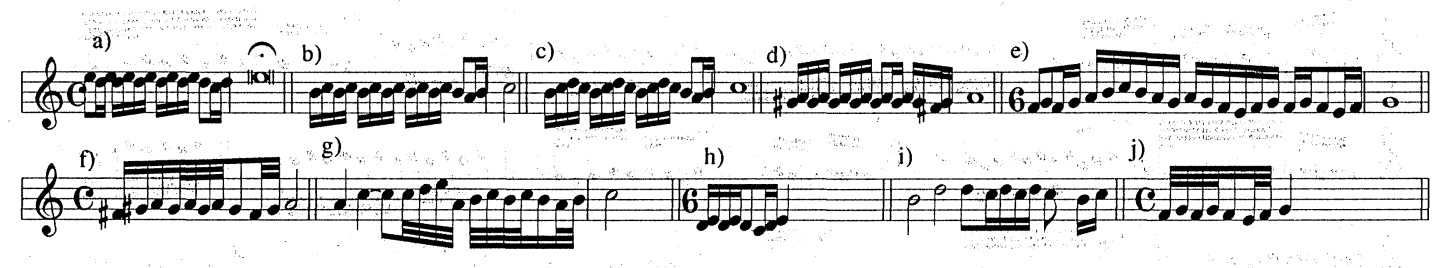


En valor de Semibreve: a) comenzando por la superior preparada, b) lento con resolución lenta, c) trino a base de grupos, d) con detención a la mitad del trino. Con valor de un compás de Sexquiáltera a 12: e) con gran grupo inicial. Con valor de Mínima: f) comenzando por nota inferior, g) con grupo inicial. En Mínima en Sexquiáltera: h) normal, i) comenzando por la superior preparada, siempre en tercera parte de compás, y formando grupo irregular (cinco corcheas en lugar de cuatro). En Semínima en Compasillo: j).

\section{Trino continuo}

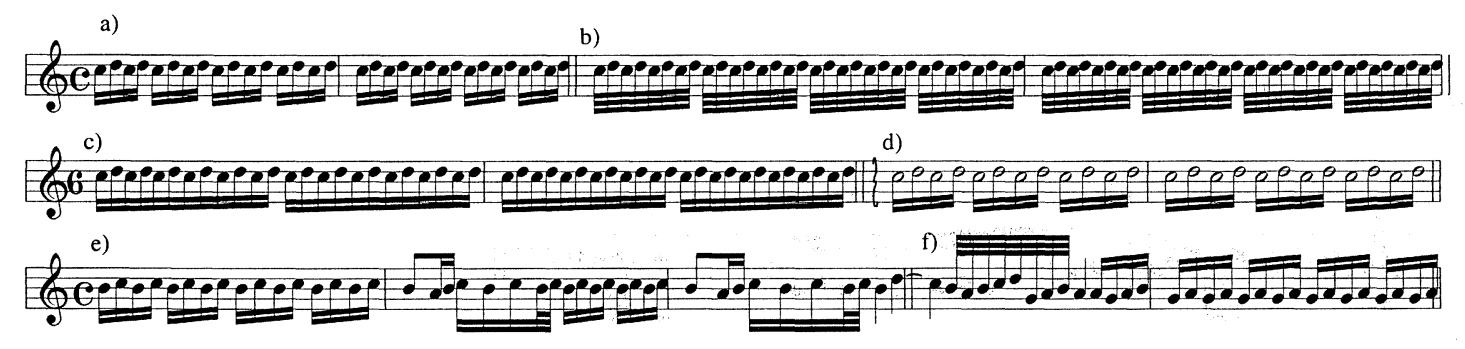

a) lento, b) rápido, c) en Sexquiáltera, d) en proporción menor, e) con detenciones cada compás, f) con grupo inicial.

Trino largo a la nota inferior

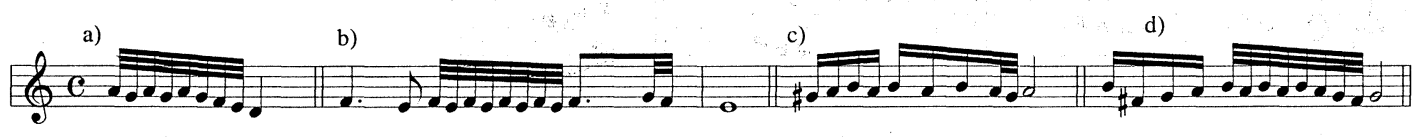

a) En valor de mínima, descendiendo $5^{\text {a }}$, b) con detención y "resolución inversa", c) y d) con grupo inicial.

\section{Trino corto}

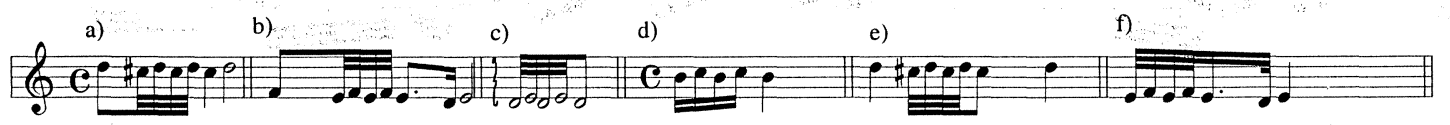

Anticipados: a) rápido, b) rápido, seguido de bordadura con ritmo punteado. En el tiempo: c) rápido, en Proporción Menor, d) lento, e) rápido, f) rápido, seguido de bordadura con ritmo punteado. 


\section{Grupos}

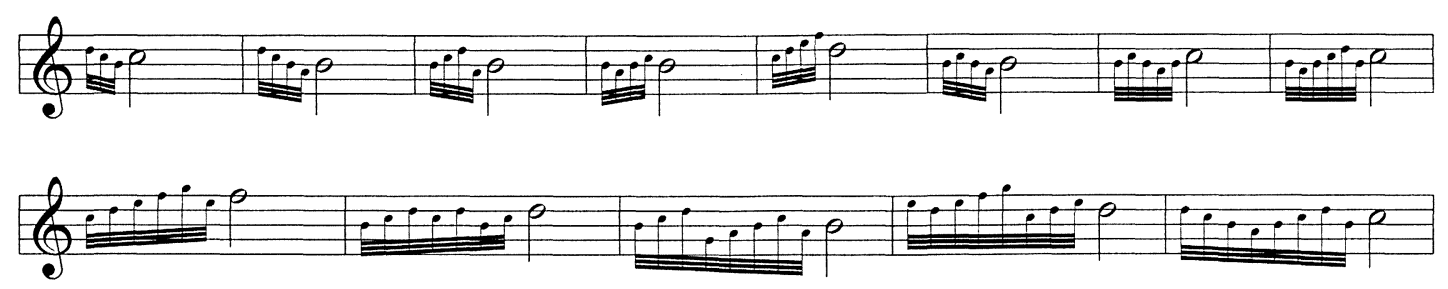

(En este caso se han esquematizado las posibilidades encontradas.)

Quiebro sencillo

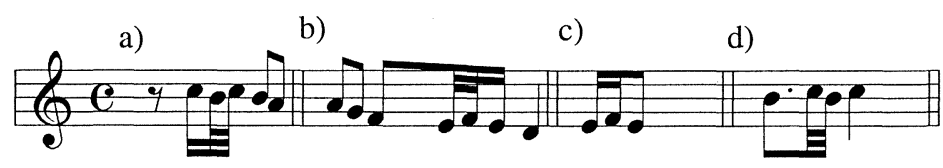

Casi siempre superior: a) anticipado, b) en el tiempo, c) lento en el tiempo, d) anticipado inferior (único caso encontrado).

\section{Figura corta}

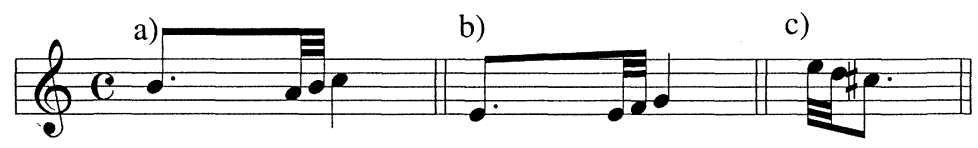

Prácticamente siempre ascendente y anticipada: a) subiendo segunda, b) subiendo tercera, c) descendente en el tiempo (único caso encontrado).

\section{Tirada}

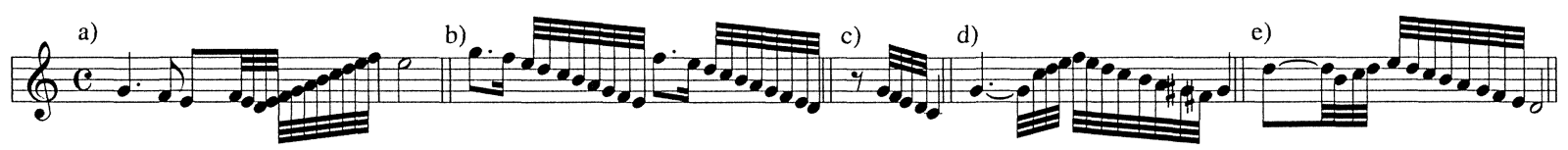

Diferentes tipos de tiradas: a) para subir una octava, b) tiradas seguidas c), tirada corta, d) para volver a la misma nota, e) para bajar una octava. 